\title{
The Embryonic Preoptic Area Is a Novel Source of Cortical GABAergic Interneurons
}

\author{
Diego M. Gelman, ${ }^{1}$ Francisco J. Martini, ${ }^{1}$ Sandrina Nóbrega-Pereira, ${ }^{1,2}$ Alessandra Pierani, ${ }^{3}$ Nicoletta Kessaris, ${ }^{4}$ \\ and Oscar Marín ${ }^{1}$ \\ ${ }^{1}$ Instituto de Neurociencias de Alicante, Consejo Superior de Investigaciones Científicas and Universidad Miguel Hernández, 03550 Sant Joan d'Alacant, \\ Spain, ${ }^{2}$ Doctoral Program in Experimental Biology and Biomedicine, Center for Neuroscience and Cell Biology, University of Coimbra, $3004-517$ Coimbra, \\ Portugal, ${ }^{3}$ Department de Biologie du Développement, Institut Jacques Monod, Centre National de la Recherche Scientifique, Unité Mixte de Recherche \\ 7592, Université Paris Diderot, 75251 Paris, France, and ${ }^{4}$ Wolfson Institute for Biomedical Research and Department of Cell and Developmental Biology, \\ University College London, London WC1E 6AE, United Kingdom
}

GABA-containing (GABAergic) interneurons play an important role in the function of the cerebral cortex. Through mostly inhibitory mechanisms, interneurons control hyperexcitability and synchronize and shape the spatiotemporal dynamics of cortical activity underlying various brain functions. Studies over the past 10 years have demonstrated that, in most mammals, interneurons originate during development from the subcortical telencephalon - the subpallium - and reach the cerebral cortex through tangential migration. Until now, interneurons have been demonstrated to derive exclusively from two subpallial regions, the medial ganglionic eminence and the caudal ganglionic eminence. Here, we show that another subpallial structure, the preoptic area, is a novel source of cortical GABAergic interneurons in the mouse. In utero labeling and genetic lineage-tracing experiments demonstrate that neurons born in this region migrate to the neocortex and hippocampus, where they differentiate into a distinct population of GABAergic interneurons with relatively uniform neurochemical, morphological, and electrophysiological properties.

\section{Introduction}

Functioning of the cerebral cortex requires the coordinated activity of excitatory neurons and inhibitory interneurons. In contrast to other regions, however, the large diversity of interneuronal populations that exists in the mammalian cerebral cortex is simply astonishing (Ramón y Cajal, 1899; Lorente de Nó, 1922; Fairén et al., 1984). As Cajal first suggested, this wealth of interneurons - his short-axon cells_-is likely responsible for the enormous computational capability acquired by this structure during evolution. Such diversity underlies many of the emergent functional properties of the cerebral cortex, from the dynamic behavior of receptor fields to the modulation of oscillatory activ-

\footnotetext{
Received Feb. 5, 2009; revised June 3, 2009; accepted June 8, 2009.

This work was supported by grants from Spanish Government SAF2008-00770, CONSOLIDER CSD2007-00023, European Commission through Specific Targeted Research Projects contract 005139 (INTERDEV0), and the European Young Investigator Award scheme award (see www.esf.org/euryi) (0.M.). D.M.G. was the recipient of a European Molecular Biology Organization short-term fellowship and is currently an International Incoming Fellow from the Marie Curie Actions of the European Commission. F.J.M. is the recipient of a predoctoral fellowship from the Formación de Personal Universitario program of the Spanish Ministry of Science and Innovation. S.N.-P. was supported by a predoctoral fellowship from the Portuguese Foundation for Science and Technology (POCI 2010/FSE). N.K. is the recipient of a United Kingdom Medical Research Council New Investigator award. We thank M. Pérez and T. Gil for excellent technical assistance, S. A. Anderson for Nkx2-1-Cre mice, V. Pachnis and G. Schütz for Lhx6 and Cre antibodies, respectively, and John L. R. Rubenstein (Nkx5-1 and Nkx6-2), D. H. Rowitch (Olig2), F. Ruddle (Dbx1), and T. Jessell (Shh) for plasmids. We are very grateful to William Richardson for his support in the generation of BAC transgenic mice and to Miguel A. Valdeolmillos for sharing his electrophysiological setup, critical reading of this manuscript, and continuous support to the project. We are also thankful to members of the Marín, Rico, and Borrell Laboratories for helpful discussions and comments.

Correspondence should be addressed to Dr. Oscar Marín at the above address. E-mail: 0.marin@umh.es.

D01:10.1523/JNEUROSCI.0604-09.2009

Copyright $\odot 2009$ Society for Neuroscience $\quad$ 0270-6474/09/299380-10\$15.00/0
}

ity and its synchronization (Gupta et al., 2000; McBain and Fisahn, 2001; Hensch, 2005; Klausberger and Somogyi, 2008).

Increasing evidence suggests that GABAergic interneurons in the isocortex and hippocampus belong to probably $>20$ distinct neuronal populations, which can be defined on the basis of their morphological, electrophysiological, and neurochemical characteristics (Freund and Buzsáki, 1996; Kawaguchi and Kondo, 2002; Markram et al., 2004; Somogyi and Klausberger, 2005). In general, these groups of interneurons have relatively homogeneous intrinsic electrical properties, reinforcing the view that they belong to distinct classes of cells. Although we are far from realizing the extent of this diversity (Petilla Interneuron Nomenclature Group et al., 2008), understanding the origin of the distinct classes of interneurons may help us to identify the logic behind their integration into cortical circuits and, eventually, their function.

With the possible exception of human and nonhuman primates (Letinic et al., 2002), cortical GABAergic interneurons seem to derive almost exclusively from the subpallium in all vertebrates studied so far (Anderson et al., 1997, 2002; Cobos et al., 2001a; González et al., 2002; Stühmer et al., 2002; Brox et al., 2003; Tuorto et al., 2003; Mueller et al., 2006; Fogarty et al., 2007; Métin et al., 2007; Xu et al., 2008) and reach the cortex through a long tangential migration (Corbin et al., 2001; Marín and Rubenstein, 2001, 2003; Métin et al., 2006). In particular, the medial ganglionic eminence (MGE) and the caudal aspect of the lateral ganglionic eminence (cLGE) [also known as the dorsal aspect of the caudal ganglionic eminence (dCGE)] have been suggested to generate most cortical GABAergic interneurons (Xu et al., 2004). 


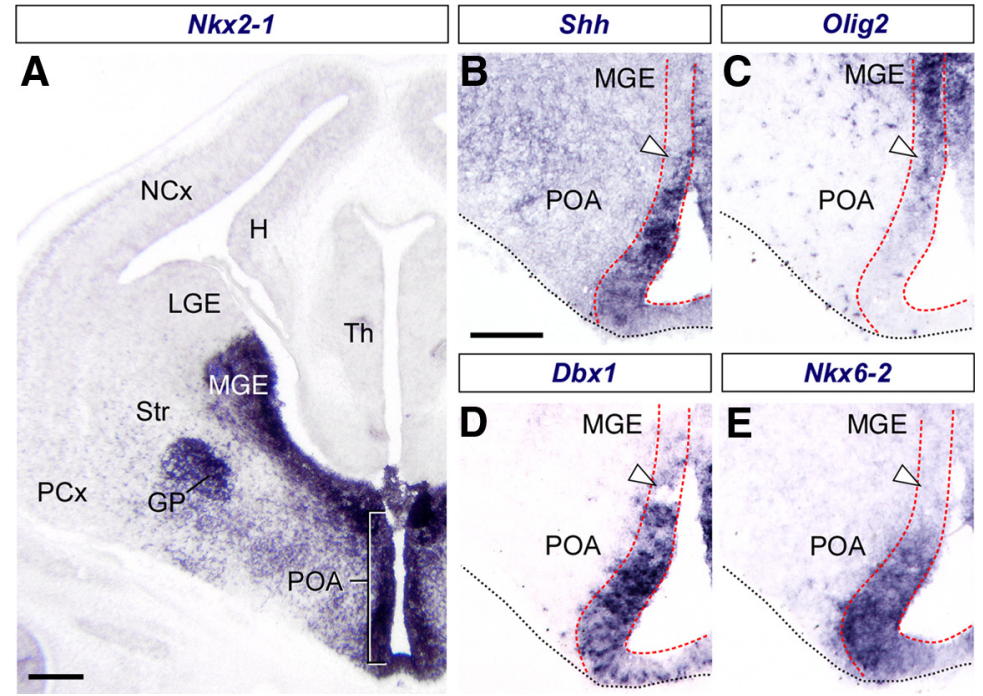

Figure 1. Molecular characterization of progenitor cells in the embryonic POA. $\boldsymbol{A}-\boldsymbol{E}$, Coronal sections through the cauda telencephalon at E13.5 showing the expression of Nkx2-1 (A), Shh (B), Olig2 (C), Dbx1 (D), and Nkx6-2 (E) mRNA. Sections $\boldsymbol{B}-\boldsymbol{E}$ are from the same brain and are adjacent to each other. The red dashed lines mark the ventricular zone, whereas the white arrowheads mark the limit between the MGE and the POA. GP, Globus pallidus; H, hippocampus; NCx, neocortex; PCx, piriform cortex; Str, striatum; Th, thalamus. Scale bars: $\boldsymbol{A}, 50 \mu \mathrm{m} ; \boldsymbol{B}-\boldsymbol{E}, 100 \mu \mathrm{m}$.

These studies, however, have not ruled out the possibility that specific classes of interneurons may derive from other subpallial sources. Indeed, in vitro studies have suggested that the rostral LGE and the subpallial septum may also give rise to cortical GABAergic interneurons (Jiménez et al., 2002; Taglialatela et al., 2004), although there is yet little in vivo support for this possibility. Here, we tested the hypothesis that the embryonic preoptic area (POA) is a source of cortical GABAergic interneurons. Using in utero electroporation and in vivo genetic lineage tracing, we found that the embryonic POA give rise to at least a distinct class of cortical interneurons. These results reinforce the view that cortical interneuron diversity arises to a large extent from the spatial segregation of distinct progenitor cells within the subpallium, and open up the venue for future studies aimed at characterizing the complete repertoire of cortical GABAergic interneurons that may derive from this novel source.

\section{Materials and Methods}

Mouse lines. CD1 wild-type embryos were used for expression analyses and in utero transplantation experiments. Nkx2-1-Cre (Xu et al., 2008), Nkx5-1-Cre, Lhx6-Cre (Fogarty et al., 2007), and Rosa-EYFP (Srinivas et al., 2001) transgenic mice were maintained in a mixed C57BL/6 $\times 129 /$ SvJ $\times$ CBA background. BAC transgenic Nkx5-1-Cre mice were generated as previously described (Fogarty et al., 2005). The BAC used to generate these mice spanned $\sim 200 \mathrm{~kb}$ of genomic DNA around the Nkx5-1 locus and was purchased from BacPac Resources. The codonimproved Cre recombinase (iCre) with a nuclear localization signal was fused to the translation initiation codon using an approach based on the PCR, and followed by an SV40 polyadenylation signal. The day of vaginal plug was considered to be embryonic day 0.5 (E0.5). Animals were kept at the Instituto de Neurociencias de Alicante under Spanish and European Union regulation.

In utero electroporation. Timed-pregnant Nkx2-1-Cre females were deeply anesthetized, and the abdominal cavity was cut open. Embryos were exposed in the uterus, and $1 \mu \mathrm{l}$ of a $1 \mu \mathrm{g} / \mu \mathrm{l}$ solution of pCAGGSLoxP-STOP-LoxP-EGFP plasmid was injected into the lateral ventricle of the telencephalon through the uterine wall. Square electric pulses of 35 $\mathrm{V}$ and $50 \mathrm{~ms}$ were passed through the uterus five times, spaced $950 \mathrm{~ms}$, using a square pulse electroporator (CUY21E; Nepa GENE). DNA was specifically electroporated into the subpallium, as described previously (Borrell et al., 2005).

In situ hybridization and immunohistochemistry. For in situ hybridization, embryonic brains were fixed overnight in $4 \%$ paraformaldehyde (PFA) and embedded in Tissue-Tek OCT compound (Sakura Finetek). Twenty micrometer frozen sections were hybridized with digoxigenin-labeled probes as described previously (Flames et al., 2007). For immunohistochemistry, embryonic brains were fixed in $4 \%$ PFA at $4^{\circ} \mathrm{C}$ from 2 to $6 \mathrm{~h}$. Brains were then embedded and cut frozen at $20 \mu \mathrm{m}$ in the cryostat or sectioned in the vibratome at $60 \mu \mathrm{m}$. Postnatal mice were anesthetized with an overdose of sodium pentobarbital and transcardially perfused with $4 \%$ PFA. Postnatal brains were removed, fixed for $1-3 \mathrm{~h}$ at $4^{\circ} \mathrm{C}$, and cryoprotected in $30 \%$ sucrose in PBS. Brains were then cut frozen on a sliding microtome at 40 $\mu \mathrm{m}$. The following primary antibodies were used: rat anti-5-bromo-2'-deoxyuridine (BrdU) (1:100; Accurate), mouse anti-Cre (1: 2000; a gift from G. Schütz), rabbit antiCyclinD1 (1:1; Thermo Fisher Scientific), rabbit anti-GABA (1:1000; Sigma-Aldrich), chicken anti-green fluorescent protein (GFP) (1:3000; Aves Labs), rabbit anti-Lhx6 (1:1000; a gift from V. Pachnis), rabbit anti-NG2 (1:200; Millipore Bioscience Research Reagents), rabbit anti-Nkx2-1 (1:2000; Biopat), mouse anti-neuronal nuclei (NeuN) (1:500; Millipore Bioscience Research Reagents), rabbit anti-neuronal isoform of nitric oxide synthase (nNOS) (1:1000; Immunostar), rabbit anti-PH3 (1:500; Millipore), rabbit anti-parvalbumin (PV) (1:5000; Swant), rat antisomatostatin (SST) (1:200; Millipore Bioscience Research Reagents), rabbit anti-S100 (1:1000; Sigma-Aldrich), rabbit anti-calretinin (CR) (1: 3000; Swant), and rabbit anti-vasointestinal peptide (VIP) (1:1000; Immunostar). The following secondary antibodies were used: goat antichicken 488 , donkey anti-rabbit 555 , donkey anti-mouse 555 (all from Invitrogen) and donkey anti-rat Cy3 (Jackson ImmunoResearch Laboratories). The immunofluorescence detection of enhanced yellow fluorescent protein (EYFP) was performed using an anti-GFP antibody. DAPI (4',6'-diamidino-2-phenylindole) (Sigma-Aldrich) was used for fluorescent nuclear counterstaining. Nkx5-1-derived cells were mapped using a microscope equipped with Neurolucida software.

Slice preparation and recordings. A vibratome was used to cut coronal slices $(300 \mu \mathrm{m})$ through the somatosensory cortex of postnatal day 17 (P17) to P22 Nkx5-1-Cre;Rosa26R-YFP mice. Slices were cut in ice-cold modified artificial CSF (aCSF) $(248 \mathrm{~mm}$ sucrose, $3 \mathrm{~mm} \mathrm{KCl}, 0.5 \mathrm{~mm}$ $\mathrm{CaCl}_{2}, 4 \mathrm{~mm} \mathrm{MgCl}_{2}, 1.25 \mathrm{~mm} \mathrm{NaH}_{2} \mathrm{PO}_{4}, 26 \mathrm{~mm} \mathrm{NaHCO}_{3}$, and $10 \mathrm{~mm}$ glucose, saturated with $95 \% \mathrm{O}_{2}$ and $5 \% \mathrm{CO}_{2}$ ) and stored in a warmed $\left(32^{\circ} \mathrm{C}\right)$ incubation chamber for at least $30 \mathrm{~min}$ before recording submerged in aCSF ( $124 \mathrm{~mm} \mathrm{NaCl}, 3 \mathrm{~mm} \mathrm{KCl}, 2 \mathrm{~mm} \mathrm{CaCl}_{2}, 1 \mathrm{~mm} \mathrm{MgCl}_{2}, 1.25$ mu $\mathrm{NaH}_{2} \mathrm{PO}_{4}, 26 \mathrm{~mm} \mathrm{NaHCO}_{3}$ and $10 \mathrm{~mm}$ glucose, saturated with $95 \%$ $\mathrm{O}_{2}$ and $5 \% \mathrm{CO}_{2}$ ). For whole-cell recordings, slices were individually transferred to the stage of an upright Leica DMLFSA microscope coupled to a confocal spectral scanning head (Leica TCS SL) and viewed through a $20 \times$ water-immersion objective. Slices were continuously superfused with aCSF at room temperature or warmed at $30^{\circ} \mathrm{C}$. Glass microelectrodes (borosilicate; $1.5 \mathrm{~mm}$ outer diameter $\times 0.86$ inner diameter; Harvard Apparatus; 3-6 $\mathrm{M} \Omega$ resistance) were filled with a potassiumgluconate-based intracellular solution $(140 \mathrm{~mm}$ K-gluconate, $10 \mathrm{~mm}$ HEPES, 2 mм NaCl, 4 mм KCl, 4 mм ATP, 0.4 mм GTP, 0.6 mм Alexa 555 ) containing $2 \mathrm{mg} / \mathrm{ml}$ biocytin for postrecording immunocytochemistry. To visualize and target cells, yellow fluorescent protein (YFP)positive neurons were excited at $488 \mathrm{~nm}$. To visualize targeted cells after whole-cell configuration, Alexa 555 was excited at $543 \mathrm{~nm}$. Interneurons were kept under current-clamp configuration with an Axoclamp 200A amplifier operating in a fast mode, filtered on-line at $2 \mathrm{kHz}$, and acquired 
on a personal computer at a sampling rate of $20 \mathrm{kHz}$ using pClamp 6.0.2 software program. To characterize the electrophysiological parameters of the cells, we applied prolonged ( $5 \mathrm{~s})$ and short-duration $(0.5 \mathrm{~s})$ hyperpolarizing and depolarizing current steps. Data analysis was performed off-line in Clampfit 9.2. The morphological reconstruction of recorded interneurons was performed using a microscope equipped with Neurolucida software. Electrophysiological parameters were calculated as follows: steady-state frequency is the reciprocal of the average of the last five interspike intervals; onset frequency is the reciprocal of the first or second interspike interval; adaptation is the percentage of reduction of the steady-state frequency with respect to the onset spike frequency (for each cell, the adapting value was calculated as the average of all saturated adapting traces). For the classification of interneurons, we followed that recently adopted by the Petilla Interneuron Nomenclature Group et al. (2008).

Quantification. For the birth dating of cortical YFP-expressing cells, YFP/BrdU double-labeled cells were counted using Neurolucida software from four different rostrocaudal levels of the cortex for three animals. To examine differences across populations, data were statistically analyzed using $\chi^{2}$ tests. For the quantification of colocalization patterns [YFP/NeuN, YFP/GABA, and YFP/Neuropeptide Y (NPY)], labeled cortical cells were counted from four different sections throughout the rostrocaudal extent of the cortex. In all cases, data were expressed as average \pm SEM.

\section{Results}

\section{Progenitor cells in the POA are different from those in} the MGE

The embryonic anterior POA is defined anatomically as the region immediately in front of the optic recess, at the limit between the telencephalon and the diencephalon. The POA is therefore part of the telencephalic stalk, the non-evaginated telencephalon (Puelles et al., 2000). The POA is also immediately adjacent to the MGE, and, as in this region, virtually all progenitor cells in the POA express the homeobox transcription factor Nkx2-1 (Flames et al., 2007) (Fig. 1A). However, expression of the transcription factor Dbx1 and the morphogenetic protein Shh can be detected in the POA ventricular zone (VZ), but not in the MGE, whereas Olig2, a transcription factor expressed at high levels in MGE progenitors, is virtually absent from the POA VZ (Fig. $1 B-D$ ). Other features distinguish the embryonic POA from the adjacent MGE. For example, the POA VZ contains cells that express Nkx6-2, whereas the adjacent ventral domain of the MGE does not (Fig. $1 E)$. Moreover, the POA does not seem to contain a pool of secondary progenitors organized in a SVZ, as it is the case for the MGE and other telencephalic regions (data not shown). Thus, POA progenitors appear to be molecularly distinct from those in the MGE (Flames et al., 2007), although expression of common transcription factors indicates that they may share some properties. Of particular interest is the expression of $N k \times 2-1$, because this transcription factor has been previously associated with progenitor cells giving rise to highly motile neurons in the MGE (Wichterle et al., 1999; Nery et al., 2002). This observation prompted us to test the hypothesis that POA progenitors, like those in the MGE, may also generate long-range migrating cells, such as cortical interneurons.

\section{The embryonic POA gives rise to cells that migrate to the cortex}

Despite the substantial number of studies analyzing the derivatives of the ganglionic eminences (Corbin et al., 2001; Marín and Rubenstein, 2001; Wonders and Anderson, 2006), virtually nothing is known about the destiny of neurons generated in the embryonic POA. Fate-mapping analysis of cells derived from the Nkx2-1 lineage in the telencephalon suggests that the embryonic $\mathrm{POA}$ gives rise to at least some parts of the adult preoptic area $\mathrm{Xu}$
A
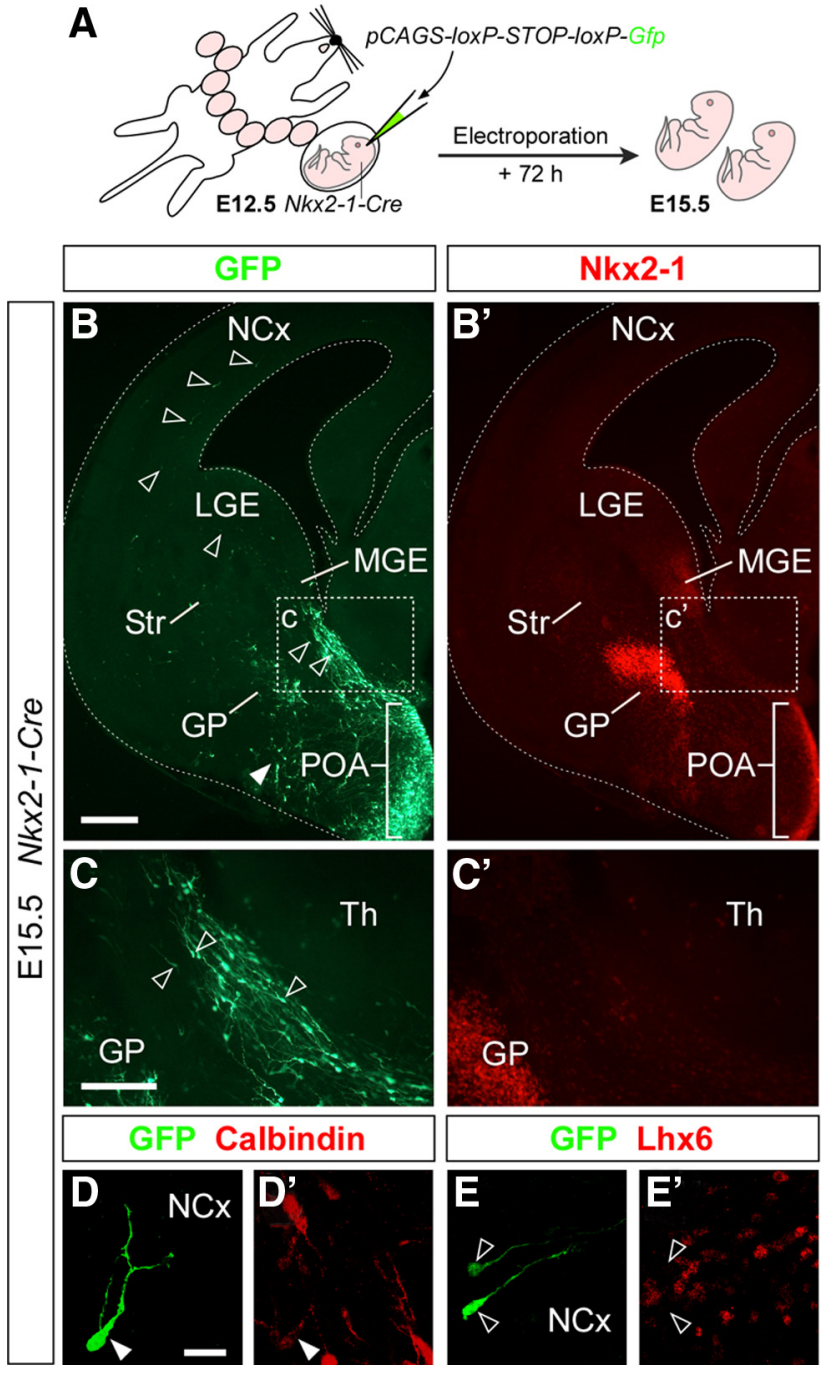

Figure 2. The embryonic POA gives rise to cells that migrate to the cortex. $A$, Schema of the experimental design followed in $\boldsymbol{B}-\boldsymbol{E}^{\prime} . \boldsymbol{B}, \boldsymbol{B}^{\prime}$, A representative case of the distribution of GFP $(\boldsymbol{B})$ - and Nkx2-1 ( $\left.\boldsymbol{B}^{\prime}\right)$-expressing cells in a coronal section through the telencephalon of an E15.5 embryo in which the POA was electroporated at E12.5. The white arrowhead indicates the location of basal forebrain cells derived from the POA. $C, C^{\prime}$, High-magnification images of the boxed areas shown in $\boldsymbol{B}$ and $\boldsymbol{B}^{\prime}$, respectively. The open arrowheads in $\boldsymbol{B}$ and $\boldsymbol{C}$ mark labeled cells with migratory morphology in the subpallium and in the cortex. $\boldsymbol{D}, \boldsymbol{D}^{\prime}, \boldsymbol{E}, \boldsymbol{E}^{\prime}$, Images of representative cells found in the cortex. These cells typically stain for Calbindin $\left(\boldsymbol{D}, \boldsymbol{D}^{\prime}\right)$ and do not express $L \mathrm{~L} \times 6\left(\boldsymbol{E}, \boldsymbol{E}^{\prime}\right)$. Scale bars: (in $\boldsymbol{B}) \boldsymbol{B}, \boldsymbol{B}^{\prime}, 250 \mu \mathrm{m}$; (in $\boldsymbol{C} \boldsymbol{C}, \boldsymbol{C}^{\prime}, 100 \mu \mathrm{m}$; (in $\left.\boldsymbol{D}\right) \boldsymbol{D}, \boldsymbol{D}^{\prime}, \boldsymbol{E}, \boldsymbol{E}^{\prime}, 25 \mu \mathrm{m}$.

et al., 2008), although no specific fate-mapping analysis has been performed for this region exclusively. In addition, early slice culture studies hinted to the possibility that neurons derived from the POA might migrate to the cortex (Marín et al., 2001), although this idea has mostly gone unnoticed (Butt et al., 2005; Métin et al., 2006; Wonders and Anderson, 2006). To directly test this hypothesis, we performed a series of in utero electroporation experiments in which we targeted a plasmid encoding for Gfp in the embryonic preoptic area at E12.5. It has been reported that adjusting the angle of inclination of the electrode paddles at $\sim 30^{\circ}$ with respect to the horizontal plane of the brain results in the specific electroporation of the ganglionic eminences (Borrell et al., 2005). A caveat of this approach, however, is that most attempts result in the labeling of progenitor cells throughout the entire subpallium (Borrell et al., 2005). To limit the target region for the electroporation, we combined this approach with the Cre/ loxP recombination system. In brief, we constructed a plasmid in 


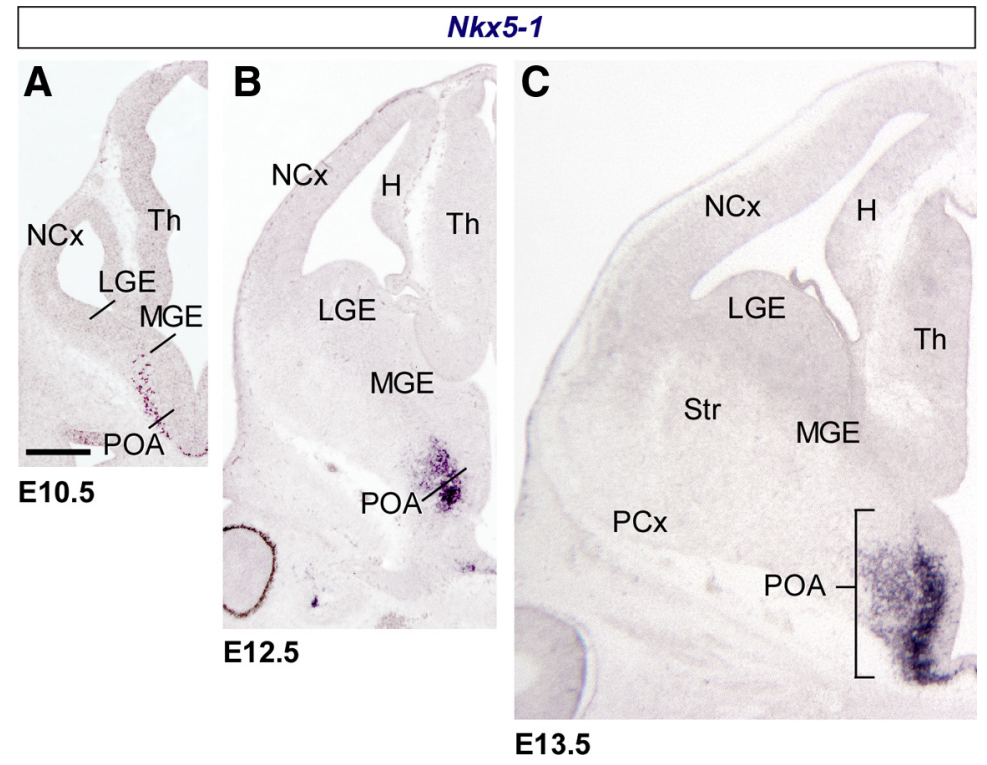

Figure 3. Restricted expression of $N k \times 5-1$ in the developing preoptic area. $A-C$, Coronal sections through the caudal telencephalon at E10.5 (A), E12.5 (B), and E13.5 (C) showing the expression of Nkx5-1 RNA. H, Hippocampus; NCx, neocortex; PCx, piriform cortex; Str, striatum; Th, thalamus. Scale bars: (in $A) A-C, 50 \mu \mathrm{m}$.

which expression of Gfp was dependent on Cre-mediated recombination, and used this vector to target the ventral telencephalon of E12.5 Nkx2-1-Cre transgenic mouse embryos (Fig. 2A). In these experiments, expression of $G f p$ was always limited to the Nkx2-1-expressing region of the telencephalon (MGE and POA), and occasionally, expression was restricted to the embryonic POA $(n=4)$ (Fig. $\left.2 B, B^{\prime}\right)$. Analysis of mouse embryos in which the POA was specifically targeted revealed numerous GFP + cells in the vicinity of the POA VZ at E15.5 (Fig. 2B). In addition, streams of cells emanating from the POA and migrating in dorsal and rostromedial directions were consistently observed at this stage in POA-electroporated embryos (Fig. 2C, $C^{\prime}$ ) (data not shown). In most cases ( $n=3$ of 4 ), migrating GFP + cells were also found in the cortex, suggesting that POA progenitors give rise to a population of cortical cells (Fig. $2 B, D, E$ ). Immunohistochemical characterization of these cells revealed that they stain for Calbindin, a common marker of immature cortical interneurons at this stage (Liu and Graybiel, 1992; Polleux et al., 2002), but many lack expression of the LIM-homeobox transcription factor Lhx6 (Fig. 2D, $E^{\prime}$ ). Because Lhx6 is a reproducible marker of cortical interneurons derived from the MGE (Lavdas et al., 1999; Fogarty et al., 2007) that is likely absent from cells emerging from the POA (Flames et al., 2007), the expression profile of cortical cells found in these experiments (Calbindin ${ }^{+} / \mathrm{Lhx6}^{-}$) reinforce the notion that interneurons derived from the POA migrate to the cortex during embryonic stages.

\section{Cortical GABAergic interneurons derive from the embryonic POA}

The previous in utero tracing experiments suggested that the POA is the origin of a population of cortical interneurons. However, because these experiments were analyzed at E15.5 to confirm that electroporation was restricted to the POA, it remained to be demonstrated that this population of POA-derived cells end up integrating in the adult cortex as GABAergic interneurons. To this aim, we performed genetic lineage experiments using again the Cre/loxP system. As part of a large effort to delineate distinct progenitor domains in the mouse subpallium (Flames et al.,
2007), we have recently found that the region immediately adjacent to the $\mathrm{VZ}$ in the most ventral aspect of the POA expresses Nkx5-1 (also known as Hmx3). Nkx5-1 appears to be transiently expressed by a population of early postmitotic POA-derived cells from midgestation to late embryonic stages (Figs. 3, 4A, $B$ ) (data not shown). Remarkably, Nkx5-1 does not seem to be expressed in other regions of the developing telencephalon (Fig. 3) (data not shown), which made this gene ideal for genetic tracing derivatives of the POA. We generated a bacterial artificial chromosome (BAC) transgenic mouse line that expresses Cre recombinase under transcriptional control of the Nkx5-1 gene to lineally label cells that are generated from the POA (supplemental Fig. S1, available at www. jneurosci.org as supplemental material). In Nkx5-1-cre mice, Cre expression in the telencephalon was restricted to the POA at all stages examined (supplemental Fig. S2, available at www.jneurosci.org as supplemental material). Moreover, when crossed to the Cre reporter mouse R26R-EYFP (Srinivas et al., 2001), we found that the pattern of YFP expression-detected with antibodies against GFP, which also recognize this fluorescent protein-at E13.5 is remarkably similar to that of the endogenous $N k \times 5-1$ gene (Fig. $4 B, C$ ). Unlike the endogenous gene, however, Cremediated recombination led to the permanent expression of YFP in those POA-derived cells that transiently expressed the Nkx5-1 gene, which allowed their tracing. Analysis of the distribution of YFP-expressing cells at different embryonic stages revealed that many of the cells that transiently expressed Nkx5-1 in the embryonic POA remain in the mantle of this region (Fig. 4D, E). However, we also found a small population of YFP-expressing cells that migrate tangentially from the POA and progressively colonize the embryonic cortex starting from E13.5 (data not shown). These cells had the typical morphology of tangentially migrating GABAergic interneurons (Fig. 4F, G), as described for example for MGE-derived cells (Lavdas et al., 1999; Martini et al., 2009). Interestingly, although some tangentially migrating YFPexpressing cells invade the cortex following a direct dorsal route (Fig. $4 C$, arrowheads), many others seem to migrate first in a rostromedial direction through the septal region to invade the cortex at intermediate and rostral telencephalic levels, both through the lateral pallium or directly through the septal region (supplemental Fig. S3, available at www.jneurosci.org as supplemental material). Once in the cortex, YFP-expressing cells migrate primarily through the marginal zone and the subplate (Fig. $4 F, G)$, but very rarely via the cortical SVZ, one of the main migratory routes for MGE- and CGE-derived interneurons (Wichterle et al., 2001; Tanaka et al., 2003).

We next analyzed the distribution of YFP-expressing cells in the telencephalon of adult Nkx5-1-Cre;Rosa26R-YFP mice. We found that many YFP-expressing cells populate medial and lateral aspects of the preoptic area (Fig. 5A), thereby demonstrating that this region mostly derives from the embryonic POA. In addition, a few YFP-expressing cells were also identified in the olfactory bulb, striatum, septum (medial, lateral, triangular, and septofimbrial nuclei), claustrum and endopiriform nucleus, the medial division of the bed nucleus of the stria terminalis, and 
several amygdala subdivisions, including the lateral, basolateral, basomedial, and medial nuclei (Fig. 5A) (data not shown). Most prominently, disperse YFPexpressing cells were found through the cerebral cortex, including the piriform cortex and the hippocampus (Fig. $5 A-C$ ) (data not shown). Immunohistochemical analysis revealed that many YFPexpressing cells found in the cortex were neurons $(39.4 \pm 2.39 \% ; n=660$ cells from two different brains), as identified by staining against the neuronal marker NeuN (Fig. 5D- $D^{\prime \prime}$ ), whereas the remaining ones stained for glial markers, such as S100 and NG2 (supplemental Fig. S4, available at www.jneurosci.org as supplemental material). Most YFP-expressing neurons in the neocortex were located in supragranular layers, independently of their birth date (Fig. 5B, D,E). Of these, a large proportion was found in layer I (Fig. $5 B, E)$.

We next investigated the molecular properties of POA-derived YFPexpressing cortical neurons. We found that virtually all of them stained with antibodies against GABA (Fig. 6A, $A^{\prime}, A^{\prime \prime \prime}$ ), reinforcing the view that the embryonic POA generates a population of cortical GABAergic interneurons. GABAergic interneurons derived from the POA distribute throughout the entire neocortex, and many were also found to populate the hippocampus (Fig. 6C). Because different classes of cortical GABAergic interneurons typically express one or several calciumbinding proteins and neuropeptides (Markram et al., 2004; Somogyi and Klausberger, 2005; Gonchar et al., 2008), we analyzed their expression in YFPexpressing neurons in the cortex. Approximately one-third of the YFP-expressing GABAergic interneurons in the cortex were found to exclusively express NPY (33.54 $\pm 2.52 \% ; n=817$ cells from three different brains) (Fig. $6 A-A^{\prime \prime \prime}, B$ ), whereas the remaining GABAergic interneurons did not stain for any of the other typical markers of these cells, including PV, CR, SST, VIP, or the nNOS (supplemental Fig. S5, available at www.jneurosci.org as supplemental material). We also analyzed the expression of the transcription factor Lhx6 in YFP-expressing neurons in the cortex. Lhx6 lies downstream of Nkx2-1 in the subpallium (Du et al., 2008), and therefore it is frequently assumed that all interneurons derived from Nkx2-1-expressing territories would also express this transcription factor. We found that virtually all YFPexpressing neurons in the cortex do not express Lhx6 at P30 (Fig. $\left.6 B-B^{\prime \prime \prime}\right)$. To confirm that $\mathrm{NPY}^{+} / \mathrm{SST}^{-}$cortical interneurons do not derive from a Lhx6-expressing lineage, we next examined the expression of NPY and SST in Lhx6-Cre;Rosa26RYFP mice (Fogarty et al., 2007). In these mice, very few $\mathrm{NPY}^{+} /$ $\mathrm{SST}^{-}$interneurons were found to derive from the Lhx6 lineage (3.10 $\pm 1.78 \% ; n=243$ cells from three different animals) (sup- plemental Fig. S6, available at www.jneurosci.org as supplemental material), whereas most $\mathrm{SST}^{+} / \mathrm{NPY}^{-}$or $\mathrm{SST}^{+} / \mathrm{NPY}^{+}$neurons did $(96.85 \pm 5.00 \% ; n=593$ cells from three different animals). In sum, YFP-expressing cortical neurons in Nkx5-1Cre;Rosa26R-YFP mice are GABAergic interneurons, frequently express NPY, and mostly derive from a Nkx2-1 ${ }^{+} / \mathrm{Lhx} 6^{-}$lineage in the POA.

\section{Nkx5-1-derived cortical interneurons constitute a functionally homogeneous population}

Although analyzing molecular properties typically represent a good way to identify distinct groups of GABAergic interneurons in the cerebral cortex (Markram et al., 2004; Gonchar et al., 2008), our failure to find any marker that labels $N k \times 5$-1-derived cortical interneurons in addition to NPY prevented us from assessing to what extent these neurons belong to two or more distinct subtypes of cortical interneurons. To address this question, 


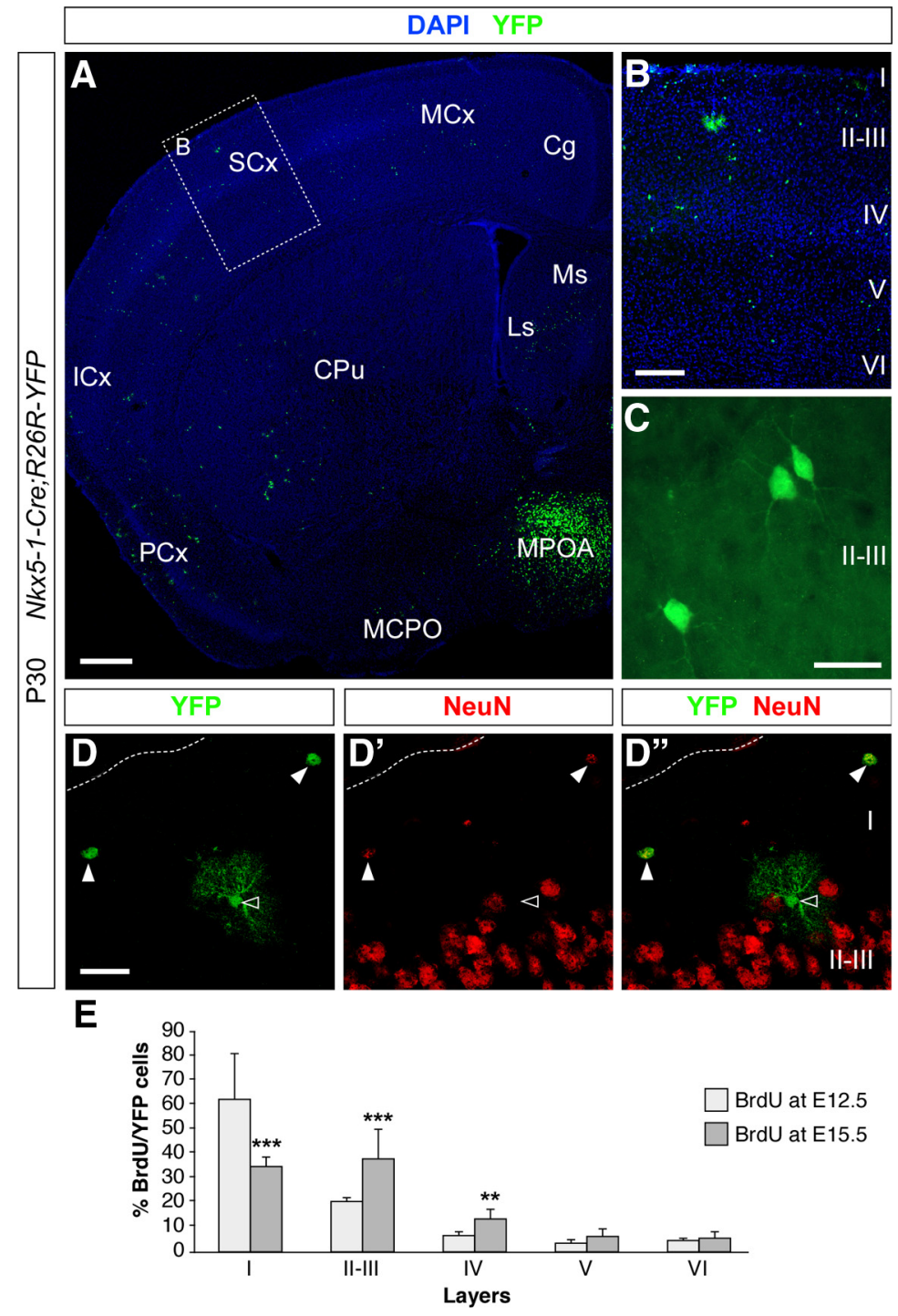

Figure 5. YFP expression in the adult telencephalon of Nkx5-1-Cre;Rosa26R-YFP mice. $A, B$, Images of a coronal section through the telencephalon of P30 Nkx5-1-Cre;Rosa26R-YFP mice showing the distribution of YFP-expressing cells. $\boldsymbol{B}$, High-magnification image of the boxed area shown in $\boldsymbol{A}$, in which the overall laminar distribution of YFP-expressing cells is visualized. Note that whereas YFP-expressing cells are abundant in medial regions of the preoptic area, very few cells are found in the region of the magnocellular preoptic nucleus (MCPO). C, Many YFP-expressing cells in the neocortex of a P30 Nkx5-1-Cre;Rosa26R-YFP mice have the morphological features of cortical interneurons. $\boldsymbol{D}-\boldsymbol{D}^{\prime \prime}$, Immunohistochemistry against $\mathrm{YFP}\left(\boldsymbol{D}, \boldsymbol{D}^{\prime \prime}\right)$ and $\operatorname{NeuN}\left(\boldsymbol{D}^{\prime}, \boldsymbol{D}^{\prime \prime}\right)$ in the neocortex of P30 Nkx5-1-Cre;Rosa26R-YFP mice. The arrowheads indicate YFP-expressing cells that express NeuN, whereas the open arrowhead points to a YFP-expressing cell that does not contain NeuN. E, Quantification of the distribution of E12.5 (light gray bars)- and E15.5 (dark gray bars)-born YFP-expressing cells in the neocortex of P30 Nkx5-1-Cre;Rosa26R-YFP mice $(n=3) .{ }^{* * *} p<$ 0.001 and ${ }^{* *} p<0.01$, t test. Error bars indicate SEM. Cg, Cingulate cortex; (Pu, caudoputamen nucleus; I-VI, cortical layers I to VI; ICX, insular cortex; Ls, lateral septum; MCX, motor cortex; MPOA, medial preoptic area; Ms, medial septum; SCX, somatosensory cortex. Scale bars: $\boldsymbol{A}, 500 \mu \mathrm{m} ; \boldsymbol{B}, 250 \mu \mathrm{m} ; \boldsymbol{C}, \boldsymbol{D}-\boldsymbol{D}^{\prime \prime}, 50 \mu \mathrm{m}$.

we recorded the electrophysiological properties of YFPexpressing cells from the somatosensory cortex of P17-P22 Nkx5-1-Cre;Rosa26R-YFP mice. In brief, YFP-expressing cells were identified under confocal microscopy and characterized in whole-cell configuration with pipettes containing the fluorescent molecule Alexa 555 (Fig. $7 A-A^{\prime \prime}$ ). More than $90 \%$ of all recorded YFP-expressing cells were excitable. Glial cells were easily identified because their fluorescence was usually more intense than interneurons and they typically appeared in clusters of two or three cells. When recorded, glial YFP-expressing cells displayed a hyperpolarized resting membrane potential and low membrane resistance $(-79.80 \pm 1.43 \mathrm{mV}, n=5 ; 80.0 \pm 10.0 \mathrm{M} \Omega, n=3$; respectively), and membrane depolarization beyond $0 \mathrm{mV}$ consistently failed to evoke action potentials (supplemental Fig. S7, available at www.jneurosci.org as supplemental material). Data from these cells were not included in our subsequent analysis.

Consistent with our previous characterization, recorded interneurons $(n=49)$ were mostly located in superficial layers of the cortex. Recorded neurons had a multipolar shape, with relatively diverse somatic, dendritic, and axonal morphologies (Fig. $7 B, D$ ). Moreover, in agreement with our previous observations, many recorded interneurons stained for NPY, but not all of them did ( $n=13$ of 16) (Fig. $7 C-C^{\prime \prime}$ ) (data not shown). Nevertheless, all interneurons recorded displayed a rather homogeneous firing pattern, with a temporal structure that was highly dependent on the stimulation level (Fig. 7E-G; supplemental Table S1, available at www. jneurosci.org as supplemental material). Recorded interneurons displayed a nonadapting and low-frequency spike behavior when near-threshold current steps were applied (range, $5-30 \mathrm{~Hz} ; n=33$ ) (Fig. 7E; supplemental Fig. S8, available at www.jneurosci.org as supplemental material). In contrast, a consistent adapting firing pattern was found in all excitable YFPexpressing cells when large depolarizing current steps were applied (adapting percentage, $79.20 \pm 1.26 \%$; range, $58-89 \%$; $n=37$ ) (Fig. 7F, G). We observed onset frequencies ranging from 99 to $574 \mathrm{~Hz}$ and steady-state frequencies from 22 to $98 \mathrm{~Hz}$. During a pulse, frequency adaptation was extremely fast, typically within the first two to five spikes, depending on the stimulus (supplemental Fig. S8, available at www.jneurosci.org as supplemental material). Moreover, when stimuli were strong enough for spikes to adapt, saturating levels of adaptation were immediately observed (supplemental Fig. S8, available at www. jneurosci.org as supplemental material). In summary, cortical neurons derived from Nkx5-1 cells in the embryonic POA belong to a rather homogenous class of rapidly adapting interneurons.

\section{Discussion}

Our results show that the embryonic POA is the source of a population of cortical GABAergic interneurons in the mouse. In utero labeling and genetic lineage-tracing experiments demonstrate that neurons born in the POA migrate to the neocortex and hippocampus, where they differentiate into a distinct population of GABAergic interneurons with relatively uniform neurochemical, morphological, and electrophysiological properties. Our findings have two major implications. First, they demonstrate 
that the POA, a progenitor region adjacent to the MGE but with different molecular properties, is a novel source of cortical GABAergic interneurons. Second, our results also suggest that unique, distinct populations of cortical interneurons can be traced to a relatively small population of spatially restricted progenitor cells in the subpallium, reinforcing the view that genetic patterning of this region into distinct populations of progenitor cells is a prominent cause of cortical interneuron diversity.

\section{The embryonic POA is a novel source of} cortical interneurons

Cortical interneurons constitute one of the most diverse groups of cells in the CNS. In fact, the variability of interneurons is so large, and defining features so diverse, than it has even been suggested that they do not exist as distinct groups, but rather as a collection of cells with a continuous spectrum of characteristics (Parra et al., 1998). Increasing evidence, however, suggests that cortical interneurons indeed belong to distinct neuronal populations (probably $>20$ distinct cell types), which can be defined on the basis of their morphological, electrophysiological, and neurochemical characteristics (Freund and Buzsáki, 1996; Kawaguchi and Kondo, 2002; Markram et al., 2004; Klausberger and Somogyi, 2008).

A large body of evidence suggests that distinct classes of interneurons originate from different regions of the subpallium (Wonders and Anderson, 2006). In particular, genetic and fate-mapping studiesprimarily in the mouse-have revealed that most cortical interneurons are born in two relatively large regions of the subpallium, the MGE and the dCGE (Sussel et al., 1999; Wichterle et al., 2001; Nery et al., 2002; Xu et al., 2003; Butt et al., 2005; Fogarty et al., 2007). Interneurons expressing PV or SST, which together account for $\sim 70 \%$ of cortical interneurons in rodents, appear to derive primarily from the MGE (Xu et al., 2003; Butt et al., 2005; Flames et al., 2007; Fogarty et al., 2007; Wonders et al., 2008), whereas bipolar cells expressing $\mathrm{CR}$, which represent $\sim 15 \%$ of the total population, seem to emerge exclusively from the dCGE (Xu et al., 2003; LópezBendito et al., 2004; Butt et al., 2005; Fogarty et al., 2007). What about the remaining types of interneurons? It has been suggested that cortical GABAergic interneurons may arise from other progenitor regions within the subpallium. For example, it has been proposed that the LGE and the embryonic septal region give rise to GABAergic neurons that migrate to the cortex (Jiménez et al., 2002; Taglialatela et al., 2004). This idea, however, is mostly based on short-term experiments, and therefore it is unclear whether cells arising from these regions ultimately differentiate into cortical interneurons. In contrast, our experiments unequivocally demonstrate the POA gives rise to a population of
YFP
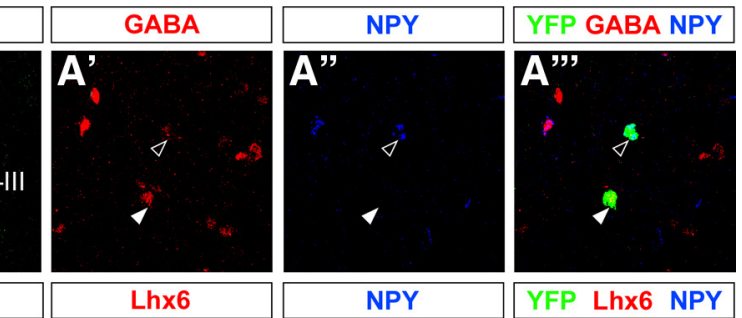

YFP
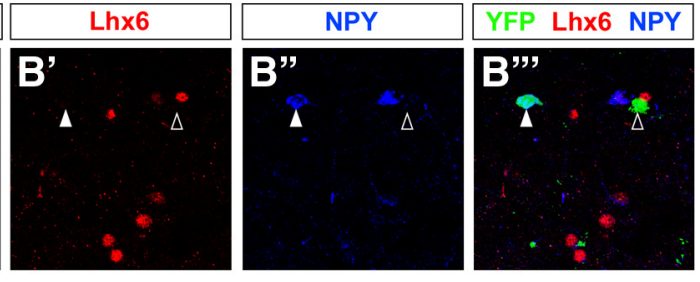

GABA

- GABA + NPY
Figure 6. Distribution of POA-derived interneurons in the neocortex and hippocampus of Nkx5-1-Cre;Rosa26R-YFP mice. $\boldsymbol{A}-\boldsymbol{A}^{\prime \prime \prime}$, , Immunohistochemistry against YFP $\left(\boldsymbol{A}, \boldsymbol{A}^{\prime \prime \prime}\right), \mathrm{GABA}\left(\boldsymbol{A}^{\prime}, \boldsymbol{A}^{\prime \prime \prime}\right)$, and NPY $\left(\boldsymbol{A}^{\prime \prime}, \boldsymbol{A}^{\prime \prime \prime}\right)$ in the neocortex of P30 Nkx5-1-Cre,Rosa26RYFP mice. The arrowhead points to a YFP-expressing neuron that expresses GABA but not NPY, whereas the open arrowhead neuron that expresses NPY but not Lhx6, whereas the open arrowhead indicates a YFP-expressing neuron that is negative for both (blue dots) in the neocortex and hippocampus of a P30 Nkx5-1-Cre;Rosa26R-YFP mouse. The schematic of the sagittal view of the mouse brain indicates the approximate location of the coronal sections drawn in $\boldsymbol{C}$ (numbers 1-6). Scale bar: (in $\boldsymbol{B}$ ) $\boldsymbol{A}-\boldsymbol{B}^{\prime \prime \prime}, 25 \mu \mathrm{m}$

GABAergic neurons that migrate to the cortex during embryonic stages and differentiate into a distinct class of cortical interneurons.

POA-derived cortical interneurons characterized in this study belong to a fairly homogenous population. These interneurons are mainly found in superficial layers of the cortex (often at the boundary between layer I and II), have a multipolar morphology, and have the intrinsic electrophysiological profile of adapting interneurons (Petilla Interneuron Nomenclature Group et al., 2008). In addition, $N k x 5$-1-derived interneurons frequently express NPY but not SST or any of the other common markers for interneurons. Since NPY levels have been shown to fluctuate in other brain nuclei (Xu et al., 1999), it is possible that all Nkx5-1derived interneurons may express NPY, in many cases below our threshold of detectability. Interneurons with similar properties have also been found to derive from the dCGE (Butt et al., 2005), a finding that is in agreement with our observation that not all 

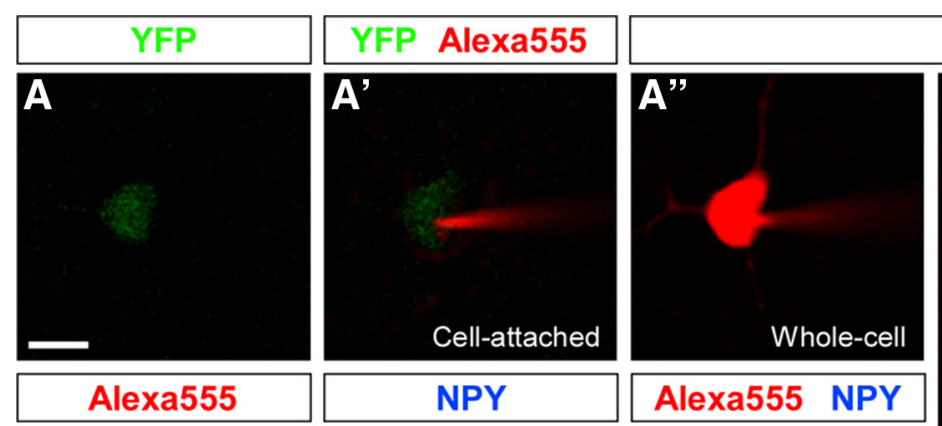

\section{Alexa555}
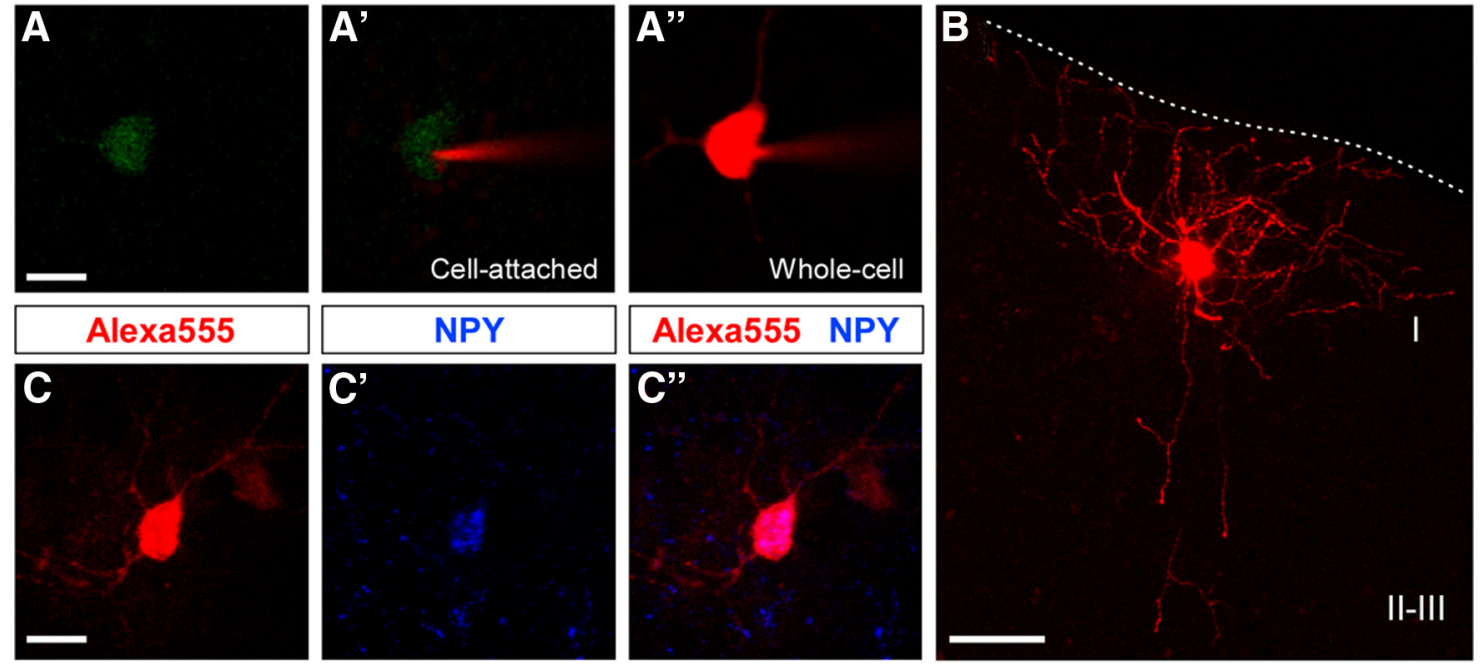

D

E
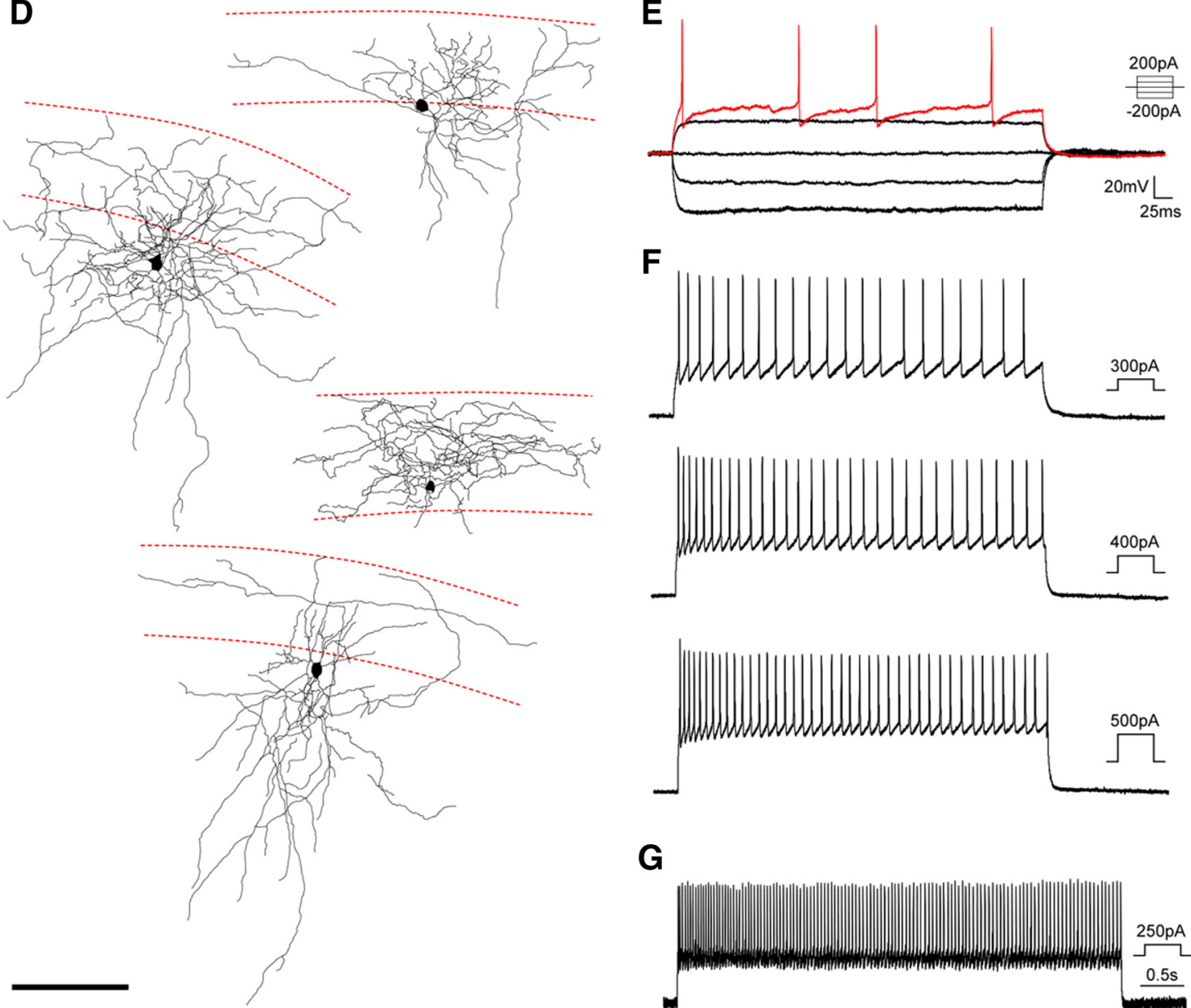

$\mathbf{F}$
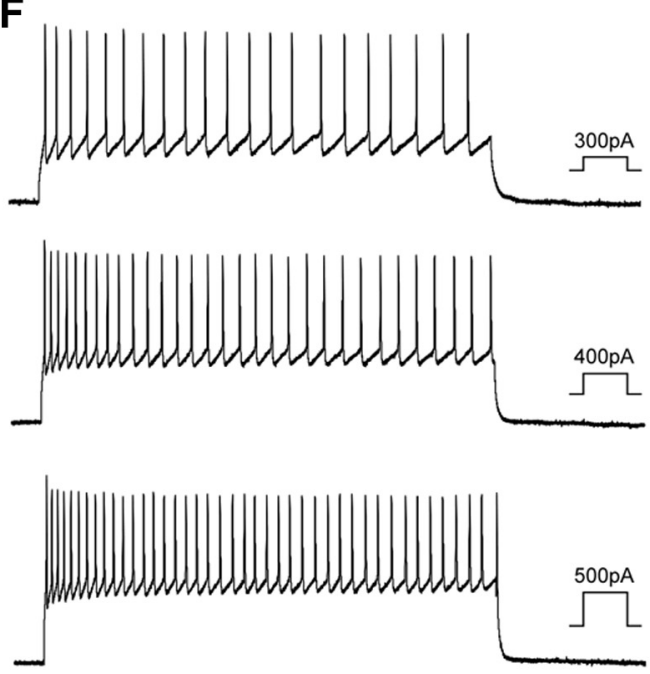

G

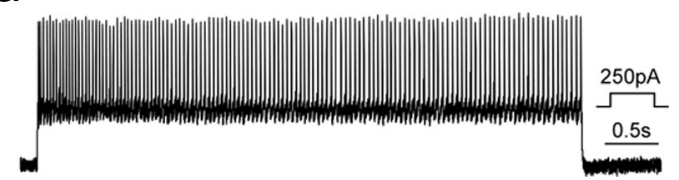

Figure 7. Cortical interneurons derived from Nkx5-1 cells constitute a relatively homogenous population with adapting firing pattern. $A-A^{\prime \prime}$, Single confocal sections acquired during initial steps of a patch-clamp recording: green fluorescence of a cortical YFP cell as seen before pipette patch $(\boldsymbol{A})$; the same cell in cell-attached $\left(\boldsymbol{A}^{\prime}\right)$ and whole-cell $\left(\boldsymbol{A}^{\prime \prime}\right)$ configuration using a pipette containing Alexa 555. B, Confocal reconstruction of a recorded cell acquired immediately after an electrophysiological session. $\mathbf{C}-\boldsymbol{C}^{\prime \prime}$, Immunohistochemistry against NPY in an Alexa 555 -containing neuron recorded in the neocortex. D, Morphological varieties of POA-derived cortical interneurons in Nkx5-1-Cre;Rosa26R-YFP mice. Images are Neurolucida reconstructions from recorded neurons. The dotted red lines indicate the limits of cortical layer I. $\boldsymbol{E}$, Current-clamp recordings in whole-cell configuration. Responses to hyperpolarizing and near-threshold depolarizing current steps. Neurons start firing at low frequency (red trace). $\boldsymbol{F}$, Larger current steps give rise to an adapting firing pattern. Increasing stimulation levels generates faster onset and steady-state frequencies. $\boldsymbol{G}$, No differences were observed applying prolonged stimulating current steps. Scale bars: $\boldsymbol{A}-\boldsymbol{A}^{\prime \prime}, \boldsymbol{C}-\boldsymbol{C}^{\prime \prime}, 10 \mu \mathrm{m} ; \boldsymbol{B}, 25 \mu \mathrm{m} ; \mathbf{D}, 100 \mu \mathrm{m}$. 
$\mathrm{NPY}^{+} / \mathrm{SST}^{-}$interneurons in the cortex derive from Nkx5-1expressing cells (data not shown). This conclusion is also consistent with the suggestion that $\mathrm{NPY}^{+} / \mathrm{SST}^{-}$cortical interneurons derive from a lineage of subpallial cells that express Dlx but not Lhx6 (Zhao et al., 2008; this study), a profile that is found both in the dCGE and in the POA (Flames et al., 2007). Thus, NPY ${ }^{+} /$ $\mathrm{SST}^{-}$cortical interneurons appear to originate from distinct progenitor pools in the dCGE and the POA.

Fate-mapping studies have shown that the embryonic POA maps close to the anterior commissure locus of the commissural plate, near the rostromedian end of the neural forebrain area (Rubenstein et al., 1998; Cobos et al., 2001b). From that perspective, it is likely that POA-derived interneurons populate the cerebral cortex in topologic rostrocaudal direction, a possibility that is consistent with the observation of a higher density of POAderived interneurons in the rostro-intermediate regions of the cortex than in intermediate-caudal areas of the cortex, both during embryonic development and in the adult brain (Fig. 6). A similar situation — although in reverse orientation — has been described for dCGE-derived interneurons, which invade the cortex through a caudal migration and therefore tend to populate more efficiently caudal cortical regions (Nery et al., 2002; Yozu et al., 2005). In the case of $\mathrm{NPY}^{+} / \mathrm{SST}^{-}$cortical interneurons, the existence of these two opposing sources (POA and dCGE) may contribute to the relatively homogenous distribution of this interneuron population throughout the entire cortex. This strategy may have been adopted during evolution to cope with the general problem of homogenously distributing a population of tangentially migrating neurons with similar properties, and may apply not only to interneurons but also to other cell types, such as Cajal-Retzius cells (Takiguchi-Hayashi et al., 2004; Bielle et al., 2005).

\section{Origin of cortical interneuron diversity}

Recent studies suggest that the generation of interneuronal diversity is linked to regional differences in the specification of progenitor cells in the subpallium (Wonders and Anderson, 2006). In the MGE, for example, progenitor cells appear to give rise to at least 10 distinct classes of cortical interneurons (Butt et al., 2005; Miyoshi et al., 2007), which can be distinguished on the basis of their morphology, neurochemical content, and electrophysiological profile. Several hypotheses have been put forward to explain, from a developmental perspective, the origin of cortical interneuron diversity. One possibility is that, as in the spinal cord (Jessell, 2000), different types of interneurons derive from discrete, spatially segregated progenitor domains, each defined by the expression of a particular combination of transcription factors (Flames et al., 2007). Consistent with this idea, it has been recently found that $\mathrm{SST}^{+} / \mathrm{CR}^{+}$Martinotti cells appear to derive primarily from the dorsal aspect of the MGE (a progenitor domain now designated as pMGE1) (Flames et al., 2007; Fogarty et al., 2007; Wonders et al., 2008), whereas fast-spiking $\mathrm{PV}^{+}$interneurons mostly originate from ventral domains of the MGE (Flames et al., 2007; Wonders et al., 2008). The current findings reinforce this idea, as we found that a relatively small progenitor domain within the subpallium generates a distinct population of cortical interneurons.

In addition, it is possible that a single progenitor domain generates more than one class of interneuron over the same developmental period. In the spinal cord, for example, motor neurons derive from a single progenitor domain, but they acquire many distinct subtype identities (i.e., columns, divisions, and pools of motor neurons) through the acquisition of different transcriptional programs (Jessell, 2000). Thus, the expression of different combinations of transcription factors in neurons derived from the same progenitor pool may contribute to increase the diversity of interneuronal subtypes (Cobos et al., 2006; Wonders and Anderson, 2006). Our present results are also consistent with this second possibility: Expression of Nkx5-1 in early postmitotic neurons derived from the POA identifies a rather homogenous population of cortical interneurons, which suggest that expression of Nkx5-1 might be somehow linked to the fate of this neuronal population. Although additional experiments would be required to test this idea, it is possible that the embryonic POA gives rise to other classes of cortical interneurons in addition to the population of $\mathrm{NPY}^{+} / \mathrm{SST}^{-}$interneurons identified in this study and that expression of Nkx5-1 only identifies one of the possible lineages originated in this region. In this context, it is worth mentioning that two distinct progenitor domains have been described within the embryonic POA (Flames et al., 2007). Thus, Nkx5-1-derived may only identify derivatives from one of these regions.

Finally, it has been suggested that interneuron diversity may also arise as a consequence of the temporal change in fate of progenitor cells (Miyoshi et al., 2007). An important implication of this idea is that environmental cues could differentially influence the maturation of different classes of interneurons, adding to their diversity. Considering the current evidence, it seem obvious that high-resolution fate-mapping studies-allowing the analysis of a very restricted number of identified progenitors or even single progenitor cells-are needed to directly determine the relative contribution of all these factors to the origin of interneuron diversity in the cerebral cortex.

\section{References}

Anderson SA, Eisenstat DD, Shi L, Rubenstein JLR (1997) Interneuron migration from basal forebrain to neocortex: dependence on Dlx genes. Science 278:474-476.

Anderson SA, Kaznowski CE, Horn C, Rubenstein JL, McConnell SK (2002) Distinct origins of neocortical projection neurons and interneurons in vivo. Cereb Cortex 12:702-709.

Bielle F, Griveau A, Narboux-Nême N, Vigneau S, Sigrist M, Arber S, Wassef M, Pierani A (2005) Multiple origins of Cajal-Retzius cells at the borders of the developing pallium. Nat Neurosci 8:1002-1012.

Borrell V, Yoshimura Y, Callaway EM (2005) Targeted gene delivery to telencephalic inhibitory neurons by directional in utero electroporation. J Neurosci Methods 143:151-158.

Brox A, Puelles L, Ferreiro B, Medina L (2003) Expression of the genes GAD67 and Distal-less-4 in the forebrain of Xenopus laevis confirms a common pattern in tetrapods. J Comp Neurol 461:370-393.

Butt SJ, Fuccillo M, Nery S, Noctor S, Kriegstein A, Corbin JG, Fishell G (2005) The temporal and spatial origins of cortical interneurons predict their physiological subtype. Neuron 48:591-604.

Cobos I, Puelles L, Martínez S (2001a) The avian telencephalic subpallium originates inhibitory neurons that invade tangentially the pallium (dorsal ventricular ridge and cortical areas). Dev Biol 239:30-45.

Cobos I, Shimamura K, Rubenstein JL, Martínez S, Puelles L (2001b) Fate map of the avian anterior forebrain at the four-somite stage, based on the analysis of quail-chick chimeras. Dev Biol 239:46-67.

Cobos I, Long JE, Thwin MT, Rubenstein JLR (2006) Cellular patterns of transcription factor expression in developing cortical interneurons. Cereb Cortex 16 [Suppl 1]:i82-i88.

Corbin JG, Nery S, Fishell G (2001) Telencephalic cells take a tangent: non-radial migration in the mammalian forebrain. Nat Neurosci 4 [Suppl]:1177-1182.

Du T, Xu Q, Ocbina PJ, Anderson SA (2008) NKX2.1 specifies cortical interneuron fate by activating Lhx6. Development 135:1559-1567.

Fairén A, DeFelipe J, Regidor J (1984) Interneuron subtypes in the cerebral cortex. In: Cerebral cortex, Vol 1, Cellular components of the cerebral cortex (Peters A, Jones EG, eds), pp 521-553. New York: Plenum.

Flames N, Pla R, Gelman DM, Rubenstein JL, Puelles L, Marín O (2007) Delineation of multiple subpallial progenitor domains by the combinatorial expression of transcriptional codes. J Neurosci 27:9682-9695.

Fogarty M, Richardson WD, Kessaris N (2005) A subset of oligodendrocytes 
generated from radial glia in the dorsal spinal cord. Development 132:1951-1959.

Fogarty M, Grist M, Gelman D, Marín O, Pachnis V, Kessaris N (2007) Spatial genetic patterning of the embryonic neuroepithelium generates GABAergic interneuron diversity in the adult cortex. J Neurosci 27:10935-10946.

Freund TF, Buzsáki G (1996) Interneurons of the hippocampus. Hippocampus 6:347-470.

Gonchar Y, Wang Q, Burkhalter A (2008) Multiple distinct subtypes of GABAergic neurons in mouse visual cortex identified by triple immunostaining. Front Neuroanat 1:3.

González A, López JM, Sánchez-Camacho C, Marín O (2002) Regional expression of the homeobox gene NKX2-1 defines pallidal and interneuronal populations in the basal ganglia of amphibians. Neuroscience 114:567-575.

Gupta A, Wang Y, Markram H (2000) Organizing principles for a diversity of GABAergic interneurons and synapses in the neocortex. Science 287:273-278.

Hensch TK (2005) Critical period plasticity in local cortical circuits. Nat Rev Neurosci 6:877-888.

Jessell TM (2000) Neuronal specification in the spinal cord: inductive signals and transcriptional codes. Nat Rev Genet 1:20-29.

Jiménez D, López-Mascaraque LM, Valverde F, De Carlos JA (2002) Tangential migration in neocortical development. Dev Biol 244:155-169.

Kawaguchi Y, Kondo S (2002) Parvalbumin, somatostatin and cholecystokinin as chemical markers for specific GABAergic interneuron types in the rat frontal cortex. J Neurocytol 31:277-287.

Klausberger T, Somogyi P (2008) Neuronal diversity and temporal dynamics: the unity of hippocampal circuit operations. Science 321:53-57.

Lavdas AA, Grigoriou M, Pachnis V, Parnavelas JG (1999) The medial ganglionic eminence gives rise to a population of early neurons in the developing cerebral cortex. J Neurosci 19:7881-7888.

Letinic K, Zoncu R, Rakic P (2002) Origin of GABAergic neurons in the human neocortex. Nature 417:645-649.

Liu FC, Graybiel AM (1992) Transient calbindin-D28k-positive systems in the telencephalon: ganglionic eminence, developing striatum and cerebral cortex. J Neurosci 12:674-690.

López-Bendito G, Sturgess K, Erdélyi F, Szabó G, Molnár Z, Paulsen O (2004) Preferential origin and layer destination of GAD65-GFP cortical interneurons. Cereb Cortex 14:1122-1133.

Lorente de Nó R (1922) La corteza cerebral de ratón (primera contribución: la corteza acústica). Trabajos del Laboratorio de Investigaciones Biológicas de la Universidad de Madrid 20:41-78.

Marín O, Rubenstein JLR (2001) A long, remarkable journey: tangential migration in the telencephalon. Nat Rev Neurosci 2:780-790.

Marín O, Rubenstein JLR (2003) Cell migration in the forebrain. Annu Rev Neurosci 26:441-483.

Marín O, Yaron A, Bagri A, Tessier-Lavigne M, Rubenstein JL (2001) Sorting of striatal and cortical interneurons regulated by semaphorinneuropilin interactions. Science 293:872-875.

Markram H, Toledo-Rodriguez M, Wang Y, Gupta A, Silberberg G, Wu C (2004) Interneurons of the neocortical inhibitory system. Nat Rev Neurosci 5:793-807.

Martini FJ, Valiente M, López Bendito G, Szabó G, Moya F, Valdeolmillos M, Marín O (2009) Biased selection of leading process branches mediates chemotaxis during tangential neuronal migration. Development 136:41-50.

McBain CJ, Fisahn A (2001) Interneurons unbound. Nat Rev Neurosci 2:11-23.

Métin C, Baudoin JP, Rakiæ S, Parnavelas JG (2006) Cell and molecular mechanisms involved in the migration of cortical interneurons. Eur J Neurosci 23:894-900.

Métin C, Alvarez C, Moudoux D, Vitalis T, Pieau C, Molnár Z (2007) Conserved pattern of tangential neuronal migration during forebrain development. Development 134:2815-2827.

Miyoshi G, Butt SJ, Takebayashi H, Fishell G (2007) Physiologically distinct temporal cohorts of cortical interneurons arise from telencephalic Olig2expressing precursors. J Neurosci 27:7786-7798.

Mueller T, Vernier P, Wullimann MF (2006) A phylotypic stage in vertebrate brain development: GABA cell patterns in zebrafish compared with mouse. J Comp Neurol 494:620-634.

Nery S, Fishell G, Corbin JG (2002) The caudal ganglionic eminence is a source of distinct cortical and subcortical cell populations. Nat Neurosci 5:1279-1287.
Parra P, Gulyás AI, Miles R (1998) How many subtypes of inhibitory cells in the hippocampus? Neuron 20:983-993.

Petilla Interneuron Nomenclature Group, Ascoli GA, Alonso-Nanclares L, Anderson SA, Barrionuevo G, Benavides-Piccione R, Burkhalter A, Buzsáki G, Cauli B, Defelipe J, Fairén A, Feldmeyer D, Fishell G, Fregnac Y, Freund TF, Gardner D, Gardner EP, Goldberg JH, Helmstaedter M, Hestrin S, et al. (2008) Petilla terminology: nomenclature of features of GABAergic interneurons of the cerebral cortex. Nat Rev Neurosci 9:557-568.

Polleux F, Whitford KL, Dijkhuizen PA, Vitalis T, Ghosh A (2002) Control of cortical interneuron migration by neurotrophins and PI3-kinase signaling. Development 129:3147-3160.

Puelles L, Kuwana E, Puelles E, Bulfone A, Shimamura K, Keleher J, Smiga S, Rubenstein JLR (2000) Pallial and subpallial derivatives in the embryonic chick and mouse telencephalon, traced by the expression of the genes Dlx-2, Emx-1, Nkx-2.1, Pax-6, and Tbr-1. J Comp Neurol 424:409-438.

Ramón y Cajal S (1899) Textura del sistema nervioso del hombre y de los vertebrados. Madrid: Moya.

Rubenstein JL, Shimamura K, Martinez S, Puelles L (1998) Regionalization of the prosencephalic neural plate. Annu Rev Neurosci 21:445-477.

Somogyi P, Klausberger T (2005) Defined types of cortical interneurone structure space and spike timing in the hippocampus. J Physiol 562:9-26.

Srinivas S, Watanabe T, Lin CS, William CM, Tanabe Y, Jessell TM, Costantini F (2001) Cre reporter strains produced by targeted insertion of EYFP and ECFP into the ROSA26 locus. BMC Dev Biol 1:4.

Stühmer T, Puelles L, Ekker M, Rubenstein JLR (2002) Expression from a Dlx gene enhancer marks adult mouse cortical GABAergic neurons. Cereb Cortex 12:75-85.

Sussel L, Marin O, Kimura S, Rubenstein JLR (1999) Loss of Nkx2.1 homeobox gene function results in a ventral to dorsal molecular respecification within the basal telencephalon: evidence for a transformation of the pallidum into the striatum. Development 126:3359-3370.

Taglialatela P, Soria JM, Caironi V, Moiana A, Bertuzzi S (2004) Compromised generation of GABAergic interneurons in the brains of $\operatorname{Vaxl}^{-1-}$ mice. Development 131:4239-4249.

Takiguchi-Hayashi K, Sekiguchi M, Ashigaki S, Takamatsu M, Hasegawa H, Suzuki-Migishima R, Yokoyama M, Nakanishi S, Tanabe Y (2004) Generation of reelin-positive marginal zone cells from the caudomedial wall of telencephalic vesicles. J Neurosci 24:2286-2295.

Tanaka D, Nakaya Y, Yanagawa Y, Obata K, Murakami F (2003) Multimodal tangential migration of neocortical GABAergic neurons independent of GPI-anchored proteins. Development 130:5803-5813.

Tuorto F, Alifragis P, Failla V, Parnavelas JG, Gulisano M (2003) Tangential migration of cells from the basal to the dorsal telencephalic regions in the chick. Eur J Neurosci 18:3388-3393.

Wichterle H, Garcia-Verdugo JM, Herrera DG, Alvarez-Buylla A (1999) Young neurons from medial ganglionic eminence disperse in adult and embryonic brain. Nat Neurosci 2:461-466.

Wichterle H, Turnbull DH, Nery S, Fishell G, Alvarez-Buylla A (2001) In utero fate mapping reveals distinct migratory pathways and fates of neurons born in the mammalian basal forebrain. Development 128:3759-3771.

Wonders CP, Anderson SA (2006) The origin and specification of cortical interneurons. Nat Rev Neurosci 7:687-696.

Wonders CP, Taylor L, Welagen J, Mbata IC, Xiang JZ, Anderson SA (2008) A spatial bias for the origins of interneuron subgroups within the medial ganglionic eminence. Dev Biol 314:127-136.

Xu B, Kalra PS, Farmerie WG, Kalra SP (1999) Daily changes in hypothalamic gene expression of neuropeptide $\mathrm{Y}$, galanin, proopiomelanocortin, and adipocyte leptin gene expression and secretion: effects of food restriction. Endocrinology 140:2868-2875.

Xu Q, de la Cruz E, Anderson SA (2003) Cortical interneuron fate determination: diverse sources for distinct subtypes? Cereb Cortex 13:670-676.

Xu Q, Cobos I, De La Cruz E, Rubenstein JL, Anderson SA (2004) Origins of cortical interneuron subtypes. J Neurosci 24:2612-2622.

Xu Q, Tam M, Anderson SA (2008) Fate mapping Nkx2.1-lineage cells in the mouse telencephalon. J Comp Neurol 506:16-29.

Yozu M, Tabata H, Nakajima K (2005) The caudal migratory stream: a novel migratory stream of interneurons derived from the caudal ganglionic eminence in the developing mouse forebrain. J Neurosci 25:7268-7277.

Zhao Y, Flandin P, Long JE, Cuesta MD, Westphal H, Rubenstein JLR (2008) Distinct molecular pathways for development of telencephalic interneuron subtypes revealed through analysis of Lhx6 mutants. J Comp Neurol 510:79-99. 